УДК 347.965.43

DOI https://doi.org/10.32849/2663-5313/2020.7.01

\title{
Александр Алименко,
}

аспирант кафедры нотариального и исполнительного процесса и адвокатуры

юридического факультета

Киевского нащионального университета имени Тараса Шевченко

\section{УЧАСТИЕ АДВОКАТА В ИСКОВОМ ПРОИЗВОДСТВЕ ПРИ РАССМОТРЕНИИ НАСЛЕДСТВЕННЫХ ДЕЛ С ИНОСТРАННЫМ ЭЛЕМЕНТОМ}

Статья посвящена исследованию особенностей участия адвоката в исковом производстве при рассмотрении наследственных дел с иностранным элементом. Проанализирована роль адвоката при оформлении и подаче искового заявления в суд в контексте владения им достаточным объемом знаний материального и проиессуального законодательства и достаточным опытом применения таких знаний на практике. Автор в научной работе обращает особое внимание на важность участия адвоката для правильного определения международной, родовой и территориальной подсудности спорных наследственных правоотношений, осложненных иностранным элементом.

На основании анализа актуальной судебной практики в категории наследственных дел с иностранным элементом автором констатируется необходимость владения адвокатом навыками изложения обстоятельств дела, которыми обосновываются исковые требования, умением сбора доказательной базы, подтверждающей такие обстоятельства. Определено, что профессиональный представитель - адвокат - играет важную роль для эффективного выяснения обстоятельств дела и способствует быстрому судебному разбирательству спора между сторонами как на стадии подготовительного производства, так и на стадии рассмотрения дела по существу. Это проявляется в непосредственной коммуникации представителя с судом и другими участниками судебного заседания в форме произнесения вступительного слова, предоставления объяснений, аргументов, ходатайств об обстоятельствах дела, доказательств и тому подобное.

Отдельное внимание в исследовании посвящено выяснению особенностей участия адвоката в исковом производстве в конкретных видах споров, возникающих из наследственных правоотношений, осложненных иностранным элементом, а именно при определении судом дополнительного срока на принятие наследства. С учетом законодательных требований и судебной практики проанализировано участие адвоката в обозначении круга ответчиков в исследуемой категории дел, определении «уважительности» или «неуважительности» причин пропуска срока для подачи заявления о принятии наследства наследником и определении способа восстановления нарушенньх прав и интересов клиентов.

Ключевые слова: адвокат, наследственные дела с иностранным элементом, исковое производство, подготовительное производство, рассмотрение дела по существу, определение дополнительного срока на принятие наследства, «неуважительные» причины пропуска срока для принятия наследства.

Постановка проблемы. Восстановление нарушенных прав и интересов лиц в наследственных правоотношениях с иностранным элементом обычно происходит в гражданском судопроизводстве в порядке искового производства. Участие адвоката в данном виде производства особенно важно и необходимо, учитывая владение им достаточным объемом знаний материального и процессуального законодательства для обращения в суд, практическим опытом их применения и возможностью содействия быстрому и эффективному судебному разбиратель- ству спорной ситуации. При этом участие в исковом производстве при рассмотрении наследственных дел с иностранным элементом характеризуется специфическими особенностями, которые требуют более детального анализа и выяснения в указанной научной статье.

Анализ последних исследований и публикаций. Теоретические и практические вопросы участия адвоката в исковом производстве при рассмотрении наследственных дел с иностранным элементом самостоятельного исследования в отечественной 
науке не находят. Так, значительное внимание посвящается общему анализу искового производства в рамках гражданского судопроизводства, в частности, в научных трудах С. С. Бычковой, С. В. Васильева, В. П. Феннич, С. Я. Фурсы, М. И. Штефана, В. В. Яркова; характеристике участия адвоката в гражданском судопроизводстве, в частности, в исследованиях Р. Ю. ХаникПосполитак, М. В. Шпака. Отдельные научные работы посвящены исследованию искового производства по гражданским делам с иностранным элементом (работы Л. М. Косовского) и анализу основных категорий наследственных дел, рассматриваемых судами в порядке искового производства (работы А. Е. Кухарева).

Целью статьи является выяснение особенностей участия и роли адвоката в исковом производстве при рассмотрении наследственных дел с иностранным элементом судом.

Изложение основного материала. Исковое производство гражданского судопроизводства выступает традиционным производством, в рамках которого решаются споры о праве в сфере гражданских (в том числе относительно наследственных), трудовых, семейных, жилищных, земельных и других отношений $[1$, c. 1]. А его сущность сводится к существованию двух противоположных по интересам сторон и спорности их имущественных и личных неимущественных правоотношений, которые передаются на рассмотрение суда [2, с. 24]. С целью профессионального и компетентного представительства прав и интересов сторон в суде может быть привлечен адвокат.

Несмотря на то, что подавляющее большинство ученых раскрывают суть искового производства через призму основного института этого вида производства - иска [3, с. 322; 4, с. 322], роль адвоката в надлежащем оформлении искового заявления с соблюдением всех законодательных требований является сверхважной. Обусловлено это тем, что обычный гражданин Украины, иностранец или лицо без гражданства не всегда обладает достаточным объемом знаний материального и процессуального законодательства для обращения в суд за защитой своих нарушенных прав и интересов или, обладая ими, не имеет достаточного опыта их применения, в отличие от профессионального юриста. Более того, актуальность участия адвоката на стадии разработки искового заявления повышается в связи с прогрессирующей тенденцией судебными инстанциями к чрезмерному формализму при реше- нии вопроса открытия производства по делу, в том числе по законодательным требованиям по оформлению иска, подтверждению полномочий адвоката в судебном процессе на осуществление представительства клиента и тому подобное.

В первую очередь, на этапе составления искового заявления в исследуемой категории дел адвокатом должна быть правильно определена подсудность наследственного дела с иностранным элементом (для определения судебной инстанции для обращения с иском) с помощью поиска и анализа норм отечественного (Закон Украины «О международном частном праве», ГПК Украины) и международного законодательства (международные соглашения в этой сфере и двусторонние договоры Украины с другими странами), регламентирующих юрисдикционные вопросы. Фактически адвокату необходимо путем основательного исследования законодательных требований определить международную, родовую и территориальную подсудность спорных наследственных правоотношений, осложненных иностранным элементом.

Важность участия адвоката на указанной стадии с точки зрения содействия суду в правильном установлении подсудности спорных правоотношений находит свое подтверждение в актуальной судебной практике. Так, например, в решении Меживского районного суда Днепропетровской области от 21 июня 2018 по гражданскому делу № $181 / 590 / 18$ по иску о признании права собственности в порядке наследования по закону хоть и была правильно установлена подсудность по наследственному делу с иностранным элементом, однако судом нарушен процессуальный порядок установления подсудности наследственного дела с иностранным элементом, а именно не были соблюдены требования ст. 75 Закона Украины «О международном частном праве» и рекомендации, установленные в письме Высшего специализированного суда Украины по рассмотрению гражданских и уголовных дел «О практике рассмотрения судами гражданских дел с иностранным элементом» от 16.05.2013 г. № 24-754 / 0/4 -13 [5], в которых речь идет об определении подсудности наследственного дела с иностранным элементом на этапе открытия производства по делу. Тогда это бы могло найти отражение в соответствующем постановлении об открытии производства с описанием позиции и обоснованиями суда по указанному вопросу (соответствующее постановление этих сведений не содержит) или на стадии подготовительного производства, относительно чего также отсутствует 
соответствующее постановление о закрытии подготовительного производства и назначении дела к судебному разбирательству по существу. Зато позиция и обоснование суда об установлении подсудности наследственного дела с иностранным элементом определяется в решении по результатам рассмотрения данного дела, что явно противоречит требованиям действующего законодательства Украины. Таким образом, привлечение более квалифицированного представительства ответчика, например адвоката, позволило бы во время апелляционного обжалования обратить внимание судебной инстанции на существующие в решении нарушения процессуального законодательства относительно установления юрисдикции и, как результат, в соответствии со ст. 374 ГПК Украины отменить судебное решение полностью или частично и принять в соответствующей части новое решение или изменить решение.

Стоит заметить, что профессионализм работы адвоката проявляется в умении изложения обстоятельств дела, которыми обосновываются исковые требования, сборе и изложении доказательств, подтверждающих данные обстоятельства. Ярким примером является правовая позиция со ссылками на доказательства, изложенная адвокатом в исковом заявления при рассмотрении судом дела № 723/1983/16-с. Так, в решении Сторожинецкого районного суда Черновицкой области от 17 января 2017 года, которое было оставлено без изменений определением Апелляционного суда Черновицкой области от 28 февраля 2017 года, сказано, что исковое заявление мотивировано тем, что после смерти наследодателя - гражданина Украины П. - на территории Федеративной Республики Германия открылось наследство. Факт смерти в иностранном государстве подтверждался свидетельством о смерти, апостилизированным в соответствии с требованиями Гаагской конвенции, отменяющей требование легализации иностранных официальных документов от 1961 года. При жизни наследодателем было составлено завещание в г. Мюнхен Федеративной Республики Германия, согласно которому все имущество завещалось пяти его дочерям А., И., Г., С., В. в разных долях. Жена Л., с которой наследодатель в момент составления завещания находился в процессе официального развода, в завещании не указывалась, как и мать наследодателя Ж. Стоит заметить, что в суд были предоставлены завещание с апостилем, что утверждает подлинность подписи и статус, в котором выступала лицо, подписавшее документ. Ответчиками по делу была предпринята попытка признать завещание, составленное наследодателем за рубежом, ничтожным в связи с тем, что оно было составлено наследодателем лично в письменной форме без удостоверения нотариусом или другим представителем власти. Однако судом указанные аргументы во внимание не были приняты, поскольку наследодатель имел последнее постоянное место жительства на территории Федеративной Республики Германия, где и умер, а потому форма завещания определяется по законодательству страны, где наследодатель имел последнее постоянное место жительства (Федеративная Республика Германия). В соответствии со ст. 2231 и ст. 2247 Германского гражданского кодекса обычное завещание может быть составлено, в частности, в форме собственноручно написанного и подписанного наследодателем заявления с указанием места и даты его составления. Также речь шла о том, что при оформлении не были соблюдены процедуры консульской легализации собрания, документы заверены только апостилем. Это, по мнению ответчиков, противоречило требованиям Гаагской конвенции, отменяющей требование легализации иностранных официальных документов от 1961 года, где по возражению Федеративной Республики Германия против присоединения Украины к указанной Конвенции украинские суды не принимают документы, заверенные апостилем. Однако при детальном выяснении обстоятельств дела и принятии во внимание аргументированной позиции представителя истца о том, что на момент составления завещания (2013 год) Федеративная Республика Германия отозвала (в 2010 году) возражения против присоединения Украины к Конвенции, а единственным способом удостоверения подлинности подписи и статуса, в котором выступало лицо, является апостиль, аргументы ответчиков были отклонены [6].

После надлежащего оформления искового заявления в соответствии с требованиями, предусмотренными ст. 175 и ст. 177 ГПК Украины, иск в наследственном деле с иностранным элементом подается в первую инстанцию суда общей юрисдикции. Суд при отсутствии оснований для оставления искового заявления без движения, возвращения искового заявления или отказа в открытии производства открывает производство по делу в течение 5 (пяти) дней со дня поступления искового заявления или заявления об устранении недостатков. Стоит отметить, что в случае рассмотрения дела в общем исковом производстве в постановлении определяется дата, время и место подготовительного заседания. 
Также в данном постановлении определяется срок и очередность предоставления сторонами дела процессуальных документов, в частности отзыва на иск, ответов на отзыв, возражений, объяснений третьих лиц.

На данном этапе участие представителя является весьма важным, ведь он может вовремя отреагировать путем предоставления необходимых процессуальных документов на аргументы противоположной стороны по делу, при необходимости уточнить исковые требования, обратиться в суд для проведения урегулирования спора с участием судьи, предоставить ходатайство о привлечении в дело других лиц (например, соответчика), предоставить дополнительные доказательства с обоснованием причины их непредставления на стадии подачи искового заявления в суд.

По результатам подготовительного заседания суд выносит одно из следующих постановлений: 1) определение об оставлении искового заявления без движения; 2) определение о прекращении производства по делу; 3) постановление о закрытии подготовительного производства и назначении дела к судебному разбирательству по существу. Указанный перечень процессуальных действий суда не является исчерпывающим, поскольку в случае признания ответчиком иска на указанной стадии может быть принято решение по делу по результатам подготовительного производства [7].

После окончания стадии подготовительного производства суд переходит к рассмотрению дела по существу. Во время указанной стадии судебного процесса представитель осуществляет непосредственную коммуникацию с судом и другими участниками судебного заседания, в частности: произносит вступительное слово, в котором кратко излагает содержание и основания требований и возражений относительно предмета иска со ссылкой на конкретные обстоятельства и доказательства, предоставляет пояснения по каждому заявленному в иске требованию, задает с разрешения председательствующего вопросы участникам дела, отвечает на вопросы участников процесса, в том числе судьи, предоставляет объяснения по поводу письменных, вещественных и электронных доказательств и тому подобное.

С учетом вышеизложенного следует дать характеристику участия адвоката в конкретных видах споров, возникающих из наследственных правоотношений, осложненных иностранным элементом, а именно при определении судом дополнительного срока на принятие наследства. По общему пра- вилу, определенному в ст. 1270 ГК Украины, срок для принятия наследства составляет 6 (шесть) месяцев с момента открытия наследства. При этом временем открытия наследства является день смерти лица или день, с которого оно объявляется умершим.

Следствием пропуска срока для принятия наследства является утрата права на получение наследства. Однако из указанного правила существуют исключения, в частности судебный способ восстановления права на подачу заявления о принятии наследства в нотариальную контору. Реализовать указанное позволит привлечение профессионального юриста - адвоката. Поскольку адвокат владеет знанием законодательных требований, имеет судебную практику, сложившуюся по решению исследуемой категории дел, он может, прежде всего, правильно определить круг ответчиков в случае подачи искового заявления об определении дополнительного срока на принятие наследства. В зависимости от существования наследников, принявших наследство и отрицающих внесудебную процедуру восстановления срока на подачу заявления о принятии наследства, или их отсутствия круг ответчиков может быть разным (например, или определение наследников, или территориальных общин в лице соответствующих органов местного самоуправления по месту открытия наследства в качестве ответчиков, или невозможность привлечения нотариальной конторы или нотариуса в качестве ответчика и т. д.), а потому роль адвоката при выяснении указанных особенностей становится актуальной и способствует быстрому и эффективному обращению в суд в интересах клиента.

Стоит заметить, что определение дополнительного срока на принятие наследства в судебном решении напрямую зависит от уважительности причин пропуска этого срока наследником. Однако в законодательстве не отражен примерный перечень причин, которые могут быть признаны судом уважительными и служить основанием для определения дополнительного срока на принятие наследства. Бесспорно, словосочетание «уважительность причин» является оценочным, зависит от обстоятельств конкретного дела и сложившейся доказательной базы. При этом адвокат, учитывая наработки судебной практики, может обоснованно определить неуважительность или уважительность причин пропуска срока для подачи заявления о принятии наследства. Так, в частности, к первой категории следует относить: 1) юридическую неосведомленность наследника о сроке и порядке 
принятия наследства; 2) неосведомленность наследника о наличии наследственного имущества; 3) преклонный возраст наследника 4) нетрудоспособность наследника; 5) незнание наследником о существовании завещания от наследодателя; 6 ) установление судом факта, имеющего юридическое значение для принятия наследства (например, установление факта проживания одной семьей); 7) неопределенность между наследниками, кто будет принимать наследство; 8) отсутствие средств для проезда к месту открытия наследства; 9) неблагоприятные погодные условия [8]. Правда, указанный перечень не является исчерпывающим и может быть расширен в зависимости от конкретных обстоятельств дела, подтвержденных соответствующими доказательствами, и от субъективного мнения представителей «фемиды» и включать следующие неуважительные причины пропуска срока для подачи заявления о принятии наследства: 1) неосведомленность о смерти наследодателя; 2) не уведомление наследника нотариусом об открытии наследства в том числе путем размещения публичного объявления в прессе; 3 ) постоянное проживание наследника за пределами Украины.

Ко второй категории, включая так называемые «уважительные» причины пропуска срока для подачи заявления о принятии наследства, следует относить длительную и тяжелую болезнь; сложные условия труда, связанные с длительными командировками, в том числе зарубежными; пребывание наследника на срочной военной службе. Указанные обстоятельства должны быть подтверждены только письменными доказательствами, в частности: 1) подтверждающими документами о длительной командировке наследника или военную службу; 2) документами, подтверждающими факт долгосрочного стационарного лечения, и тому подобное.

\section{Выводы}

Итак, участие адвоката в исковом производстве при рассмотрении наследственных дел с иностранным элементом приобретает особую актуальность, учитывая осложнения указанных правоотношений иностранным элементом, что проявляется в наличии специфического субъекта (иностранный субъект), объекта наследственных правоотношений, который находится на территории иностранного государства, или юридического факта, связанного с наследственными правоотношениями, что имели место на территории иностранного государства, а также необходимость правильного оформления искового заявления для обращения в надлежащую судебную инстанцию с учетом осложненных законодательных требований, определения международной, родовой и территориальной подсудности спорных наследственных правоотношений, осложненных иностранным элементом, необходимость последовательного изложения обстоятельств дела, которыми обосновываются исковые требования, сбора доказательной базы, подтверждающей такие обстоятельства, необходимость осуществления непосредственной коммуникации с судом и другими участниками во время судебного рассмотрения спорных правоотношений (путем предоставления ходатайств, объяснений, доводов, соображений относительно обстоятельств дела со ссылкой на соответствующие письменные, вещественные и электронные доказательства).

\section{Список использованных источников:}

1. Феннич В.П. Основания упрощенного искового производства в гражданском процессе. Материалы 72-й итоговой научной конференции профессорско-преподавательского состава Государственного высшего учебного заведения «Ужгородский национальный университет», г. Ужгород, 26-28 февраля 2018 г. Ужгород: изд-во УжНУ «Говерла», 2018. С. 1-10.

2. Васильев С. В. Гражданский процесс Украины : учебное пособие. 2-е изд., перераб. Москва : Эспада, 2010. 456 с.

3. Штефан М.И. Гражданское процессуальное право Украины: академический курс : учебник. Москва : Ин Юре, 2005. 624 с.

4. Ярков В.В. Гражданский процесс : учебник. 5-е изд., перераб. и доп. Москва : Уолтер Клувер, $2004.720 \mathrm{c}$.

5. Решение Меживского районного суда Днепропетровской области от 21.06.2018 г. по делу №.1.81/590/18. URL: http://reyestr.court.gov.ua/ Review/74845883 (дата обращения: 18.06.2020).

6. Решение Сторожинецкого районного суда Черновицкой области от 17.01.2017 г. по делу № 723/1983/16-ц. URL: http:// reyestr.court.gov.ua/Review/64191849 (дата обращения: 18.06.2020).

7. Гражданский процессуальный кодекс Украины : Закон Украины от 18.03.2004 г. № 1618IV. Ведомости Верховной Рады Украины. 2004. № 40, 40-42. Ст. 1530.

8. Постановление Кассационного гражданского суда в составе Верховного Суда от 13.05.2019 г. по делу № 639/2082/17. URL: http://reyestr.court.gov.ua/Review/81722212 (дата обращения: 18.06.2020). 
Олександр Аліменко. Участь адвоката в позовному провадженні під час розгляду спадкових справ з іноземним елементом

Стаття присвячена дослідженню особливостей участі адвоката в позовному провадженні під час розгляду спадкових справ з іноземним елементом. Проаналізовано роль адвоката в оформленні та подачі позовної заяви до суду в контексті володіння ним достатнім обсягом знань матеріального і процесуального законодавства і достатнім досвідом застосування таких знань на практиці. Автор у науковій роботі звертає особливу увагу на важливість участі адвоката для правильного визначення міжнародної, родової і територіальної підсудності спірних спадкових правовідносин, ускладнених іноземним елементом.

На підставі аналізу актуальної судової практики в категорії спадкових справ з іноземним елементом автором констатується необхідність володіння адвокатом навичками викладу обставин справи, якими обгрунтовуються позовні вимоги, вміння збору доказової бази, яка підтверджує такі обставини. Визначено, що професійний представник - адвокат - відіграє важливу роль для ефективного з'ясування обставин справи і сприяє швидкому судовому розгляду спору між сторонами як на стадії підготовчого провадження, так і на стадії розгляду справи по суті. Це проявляється в безпосередній комунікаиї представника із судом та іншими учасниками судового засідання у формі проголошення вступного слова, надання пояснень, аргументів, клопотань про обставини справи, доказів тощо.

Окрему увагу в дослідженні присвячено з'ясуванню особливостей участі адвоката в позовному провадженні в конкретних видах спорів, що виникають із спадкових правовідносин, ускладнених іноземним елементом, а саме під час визначення судом додаткового строку на прийняття спадщини. Проаналізовано з урахуванням законодавчих вимог і судової практики участь адвоката у визначенні кола відповідачів у досліджуваній категорії справ, визначенні «поважності» або «неповажності» причин пропуску строку для подання заяви про прийняття спадщини спадкоємщем $і$ визначенні способу відновлення порушених прав та інтересів клієнтів.

Ключові слова: адвокат, спадкові справи з іноземним елементом, позовне провадження, підготовче провадження, розгляд справи по суті, визначення додаткового строку для прийняття спадщини, «неповажні» причини пропуску строку для прийняття спадщини.

Oleksandr Alimenko. Lawyer's participation in action proceedings when hearing crossborder inheritance case

The article is devoted to the study of the peculiarities of the participation of a lawyer in litigation in the consideration of inheritance cases with a foreign element. The role of a lawyer in drawing up and filing a lawsuit in the context of his possession of a sufficient amount of knowledge of substantive and procedural law and sufficient experience in applying such knowledge in practice is analyzed. The author pays special attention to the importance of the lawyer's participation for the correct determination of the international, tribal and territorial jurisdiction of the disputed hereditary legal relations complicated by a foreign element.

Based on the analysis of current case law in the category of inheritance cases with a foreign element, the author states the need for a lawyer to have the skills to present the circumstances of the case, which substantiate the claims, the ability to gather evidence to support such circumstances. It is established that a professional representative - a lawyer plays an important role in effectively clarifying the circumstances of the case and facilitates the speedy litigation of the dispute between the parties both at the stage of preparatory proceedings and at the stage of consideration of the case on the merits. This is manifested in the direct communication of the representative with the court and other participants involved in the hearing, in particular in the form of an introductory speech, explanations, arguments, motions about the circumstances of the case, evidence and more.

Particular attention in the study is devoted to clarifying the specifics of the participation of a lazoyer in litigation in specific types of disputes arising from inheritance relations complicated by a foreign element, namely in determining the court additional time to accept the inheritance. The participation of a lawer in determining the range of defendants in the investigated category of cases, determining the "validity" or "disrespect" of the reasons for missing the deadline for filing an application for inheritance by the heir and determining how to restore the violated rights and interests of clients were analyzed.

Key words: lawyer, inheritance cases with a foreign element, claim proceedings, preparatory proceedings, consideration of the case, determination of an additional term for acceptance of inheritances, "disrespectful" reasons for missing the term for acceptance of inheritance. 